\title{
Sanofi-Cell Research outstanding paper award of 2012
}

\author{
Cell Research (2013) 23:1241. doi:10.1038/cr.2013.147; published online 4 November 2013
}

In this November issue of Cell Research, we are proud to announce the winners of the 4th Sanofi-Cell Research Outstanding Paper Award, which were selected from papers published in the 2012 print issues of Cell Research. The 2012 Sanofi-Cell Research Outstanding Review Article Award goes to Dr Dean Tang, for his review paper entitled "Understanding cancer stem cell heterogeneity and plasticity" [1]. The winners

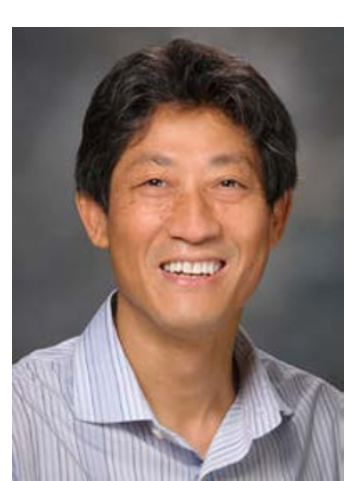
of the 2012 Sanofi-Cell Research Outstanding Research Article Award are Drs ChenYu Zhang, Ke Zen and Junfeng Zhang, for their paper entitled "Exogenous plant MIR168a specifically targets mammalian LDLRAP1: evidence of cross-kingdom regulation by microRNA" [2]; and Drs Yigong Shi and Li Yu, for their paper entitled "Crystal structure and biochemical analyses reveal Beclin 1 as a novel membrane
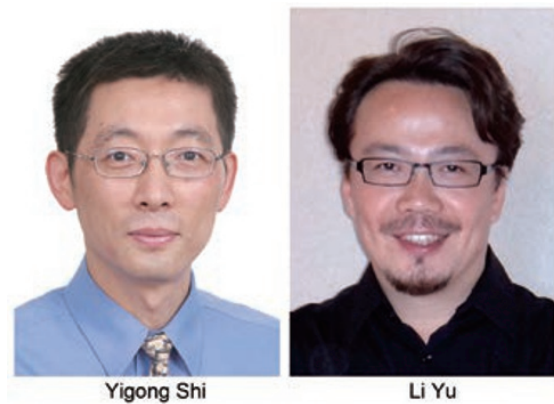

binding protein" [3]. The award consists of a prize of $€ 3000$ for the Outstanding Review Article Award and $€ 5000$ for the Outstanding Research Article Award sponsored by Sanofi. The three award-winning papers are selected based on the voting by members of the Sanofi-Shanghai Institutes for Biological Sciences Steering Committee.

The award-winning review by $\mathrm{Dr}$ Tang was published in the March issue of 2012. The review provides an expert analysis on our current understanding of cancer stem cells, with a focus on discussing their heterogeneity and plasticity. In the first award-winning research article, published in the January 2012 issue, Dr Chen-Yu Zhang and his colleagues report the discovery that a plant microRNA that is abundantly

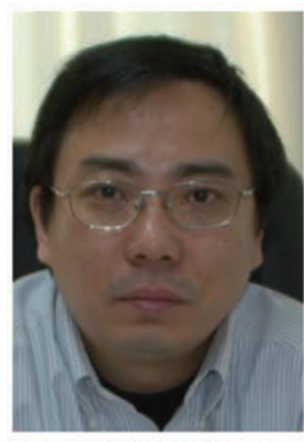

Chen-Yu Zhang

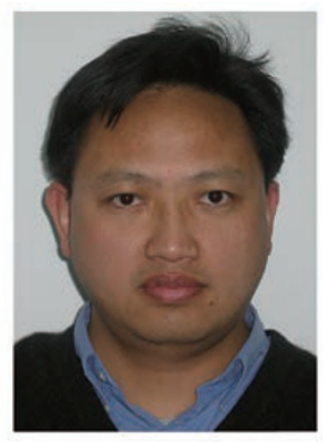

Ke Zen

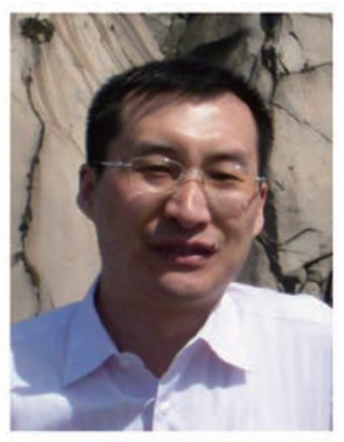

Junfeng Zhang found in rice, could be taken up by animals through food intake, and then acts to regulate the expression of a mammalian gene that is involved in host metabolism, revealing a remarkable example of cross-kingdom regulation by small RNAs. In the second awardwinning research article, published in the March 2012 issue, Drs Shi and Yu report the discovery of a novel function of Beclin 1, which is known to play an essential role in autophagy and to be a haplo-insufficient tumor suppressor. Through an elegant combination of structural and biochemical studies, they show that Beclin 1 possesses a novel membrane binding activity, thus providing important molecular insight into how this protein functions.

Please join us to congratulate the winners on their winning of the 2012 Sanofi-Cell Research Outstanding Paper Award. We hope that this yearly award program will continue to encourage our fellow scientists to submit their best work to Cell Research.

\section{Dangsheng $\mathrm{Li}^{1}$}

${ }^{1}$ Deputy Editor-in-Chief, Cell Research, Shanghai Institutes for Biological Sciences, Chinese Academy of Sciences, Shanghai 200031, China dsli@sibs.ac.cn

\section{References}

1 Tang DG. Cell Res 2012; 22:457-472.

2 Zhang L, Hou D, Chen X, et al. Cell Res 2012; 22:107-126.

3 Huang W, Choi W, Hu W, et al. Cell Res 2012; 22:473-489. 